Hofmann's students and assistants moved out into academic life as well as into industry, and thus there were some places at least where the seed which Playfair and Roscoe later scattered in their campaign for technical education fell on fertile ground.

So, though within ten years of Perkin leaving the industry, drawn by his passion for research, the decline of the industry in Britain was being lamented by Roscoe, Levinstein and others, the seeds of its future expansion were already being scattered. But we are not here concerned with why they lay dormant for over a generation or the reasons which led to the industry languishing to its near extinction, or with its brilliant renaissance in the past forty years, but to commemorate Perkin's achievement, with Hofmann and Nicholson, in founding an industry.

That Perkin was fortunate in his hour and in his times is undeniable, but the chance which placed mauve in his hands was the chance which favours the prepared mind. There was nothing haphazard or half-hearted about the way in which Perkin equipped himself for the career of research on which his mind was set, and, through those sixteen years which he spent in the industry which he, more than anyone else, created, he displayed the same determination, enthusiasm and pioneering spirit that he brought to bear in his laboratory during a long life of research. $\mathrm{He}$ could claim, with complete justification in lecturing to the Society of Arts in 1868 : "to introduce a new coal tar colour after mauve was a comparatively simple matter. The difficulties of all the raw materials had been overcome as well as the obstacles". It was not his luck but his initiative, his resourcefulness, his persistence and determination that made him the foremost technologist of his day, and the qualities and achievements which constitute Perkin's real claim to remembrance in industry are exactly those which are still needed as Britain faces the social and industrial implications of an age in which coal will no longer form the sole basis of power or of technology.

1 Trans. Chem. Soc., 69, 596 (1896); J. Soc. Dyers Col., 54, 551 (1938). ${ }^{2}$ Chem. and Indust., 515, 547 (1935).

8 "What Chemistry Owes to Chemical Science", 3rd edit., p, 120.

4 W. Crum suggests that Thomson opened his laboratory to pupils while still teaching in Edinburgh, 1801-11, Proc. Phil. Soc. Glasgow. 252 (1854).

-J. Chem. Educ., 32, 566 (1955).

- Pharm. J., 73. 187 (1931).

7 J. Soc. Dyers Col., 24, 95 (1908).

\title{
DEPARTMENT OF SCIENTIFIC AND INDUSTRIAL RESEARCH*
}

\section{ANNUAL REPORT FOR $1954-55$}

\section{Research Associations}

D URING the year 1954-55 grants were offered to three new research organizations, bringing the total of those in receipt of grant from the Department of Scientific and Industrial Research to thirty-nine, with six other co-operative industrial research organizations which have not yet reached the status of research associations. Co-operative industrial research for the glass industry has been carried out at the Department of Glass Technology, University of Sheffield, since 1915; but while this Department will continue its long-term fundamental research, the work of more direct industrial interest will be undertaken by the new Association, to which a block grant of $£ 10,000$ a year has been offered for the period April 1, 1955-March 31, 1960, conditional on $£ 20,000$ being obtained from industry, and with up to an additional $£ 12,000$ on a cent-per-cent basis from industry. The Research and Development Committee of the Timber Development Association, which has acquired new premises near High Wycombe, has been offered a block grant of $£ 14,000$ a year for the period January 1, 1955-December 31, 1957, conditional on $£ 28,000$ coming from industry, with up to a further $£ 4,000$ on the cent-per-cent basis.

New terms of grant were offered to eight research associations and research councils during the year. The British Leather Manufacturers Research Association, for the period October 1, 1954-September 30, 1956, will receive a block grant of $£ 16,000$ a year, conditional on $£ 32,000$ coming from industry, with up to a further $£ 12,000$ on a cent-per-cent basis. From October 1, 1956, to September 30,1959 , the bloek grant will be conditional on the Association receiving $£ 34,000$ from industry. A special programme of research on the dyeing and pigment.

* Continued from p. 771. finishing of leather has been commenced, and trials on goatskins in India through the monsoon indicate that sodium pentachlorophenate is effective in keeping sound skins in a good condition. Long-term investigations of the particle size of chromium complexes in solution indicate that the average size increases with the basicity of chrome tanning liquors. A method has been found by which soft and extensible leather backing can be made to adhere to glacé kid skins, and comprehensive washing trials have shown that while soap is harmless to chamois washing leathers, anionic detergents containing polyphosphates, as well as non-ionic detergents, are liable to cause damage.

The Cutlery Research Council, which for the period January 1, 1952-December 31, 1959, will receive a block grant of $£ 3,000$ a year, conditional on $£ 4,000$ coming from industry, and up to a further $£ 3,000$ on the cent-per-cent basis, continued its long-range project on the properties and heat treatment of cutlery stainless steel. In accordance with the change in emphasis to longer-term work of a more fundamental nature, projects have been initiated on the quality and characteristics of cutlery edges and a study of mechanical polishing processes and the surface finishes they produce. For the period January 1, 1955-December 31, 1959, the block grant to the Parsons and Marine Engineering Turbine Research and Development Association will be increased to $£ 40,000$ a year, conditional on $£ 100,000$ coming from industry, with up to a further $£ 30,000$ on the basis of $£ 75$ for each additional $£ 100$ from industry. Extensive tests on an experimental high-pressure, high-temperature steam turbine operating at $1100^{\circ} \mathrm{F}$. and $1,100 \mathrm{lb} / \mathrm{sq}$. in. are revealing the relative suitability of various materials for use under these conditions. An epicyclic turning gear incorporating a hydraulically operated disk brake for engage- 
ment and an automatic overload cut-out has been developed, and great advances made in the design of new bearings which have much lower power losses, greater overload capacity, and the ability to continue running after occurrence of oil failure.

The terms of grant to the British Internal Combustion Engine Research Association for the period April 1, 1954-March 31, 1957, are unchanged, providing a block grant of $£ 15,000$ a year conditional on $£ 25,000$ being received from industry, with an additional $£ 10,000$ on the usual basis. Further confirmation has been obtained of the accuracy of the Bicera method of evaluating crankshaft stiffness, and investigations of the running characteristics of a four-stroke cycle engine fitted with variable-ratio pistons continued, employing turbochargers of conventional type. Work on test rigs continued in order to determine the applicability to larger engines of previous findings in connexion with valve gear noise and a simplified form of pilot injection device, intended primarily for use with a hydro-pneumatically operated injection pump, has been developed.

The Motor Industry Research Association, which has completed its first year in its new laboratories at Lindley, near Nuneaton, will receive a block grant of $£ 30,000$ a year, conditional on $£ 80,000$ coming from industry, for the period July 1, 1955-June 30, 1960, with up to a further $£ 30,000$ on the basis of $£ 75$ for each additional $£ 100$ from industry. Work proceeded on a study of bending and torsional loads in the crankshafts of a 'square' petrol engine (in which the cylinder-bore and piston stroke are equal) and of a 10-litre, 6-cylinder, 4-stroke, compression-ignition engine. The effect of design features of cast crankshafts on the torsional fatigue strength was studied and also the causes of failure in service of splined axle shafts, and work initiated on torque converters included a critical survey of hydrokinetic, hydrostatic and mechanical converters and experimental investigation of a hydrostatic converter.

For the period October 1, 1956-September 30, 1960, the Linen Industry Research Association will receive a block grant of $\$ 15,000$ conditional on $£ 30,000$ being received from industry, with up to an additional $£ 10,000$ on the cent-per-cent basis. In its spinning research, the Association has given priority to the development of a new servo-drafting control mechanism which permits greater regularity of yarn and the spinning of finer counts, and to a modified ring system for wet spinning which gives much greater productivity. Work on the macro-structure of the flax fibre continued and a new method of testing the water-proofness of cover canvas is being developed.

The Research Council of the British Whiting Federation, which has acquired additional premises at the Hall, Welwyn, in order to undertake pilotplant work, will receive a block grant of $£ 6,000$ a year for the period January 1, 1956-September 30, 1959 , conditional on $£ 10,000$ coming from industry, with up to an additional $£ 2,000$ on the cent-per-cent basis. The efficient use of fuel in the drying processes of the industry has been studied in the works of members and numerous recommendations made leading to appreciable economies, while work on hydraulic and air methods of classifying whiting continued. For the period January 1, 1956-December 31, 1958, the Research and Information Committee of the Furniture Development Council, since April 1955 housed under one roof in premises in Holloway, will receive a block grant of $\mathfrak{£ 6 , 0 0 0}$ a year, conditional on $£ 10,000$ coming from industry, with up to a further $£ 4,000$ on the basis of $£ 80$ for each additional $£ 100$ from industry. Research on cabinet construction, particularly the structure of cabinets made from wooden frames with thin panels attached, continued, the development of performance tests for domestic furniture has been completed and efforts are being made to develop simple and accurate means of assessing the properties of finishing materials, particularly lacquers.

Of the work of the romaining research associations, only a few points of interest can be mentioned here. The fundamental work of the British Baking Industrics Research Association on natural oils in flour and bread indicates that the flour oil fraction considerably affects bread quality and is closely linked with the way in which bread quality is improved by shortenings and other substances. The British Boot, Shoe and Alljed Trades Research Association has issued a major report on the comprehensive survey of the feet of more than two thousand adult women which introduces a new way of looking at and analysing foot measurements and may profoundly affect design of the last. The British Cast Iron Research Association has developed a promising technique for sampling molten metal for hydrogen estimation, and the British Ceramic Research Association's study of the health hazards associated with the towing of the edges of plates in the fettling process and the application of correct air-flow principles substantiated by cine-photography in special lighting have led to the design of an exhaust hood which gives satisfactory control of the dust and is now being widely adopted by the industry. The British Coal Utilization Research Association's work on domestic appliances has shown that the central heating and hot-water supply demands of a house of medium size can be satisfactorily provided by a relatively small boiler of 6-10 sq. ft. heating surface, and in the trials two new systems of automatic control were developed and patented, utilizing the pressure differential available across the circulating pump. The British Coke Research Association has made further studies of the thermal conductivity of the coal charge during carbonization and of the properties of carbon and the process of carbonization. Extensive mill trials are proceeding of a hood and extraction system developed by the British Cotton Industry Research Association for fitting to carding engines, which, by reducing the dust content of the atmosphere by 90 per cent, is believed to reduce the accompanying disease of byssinosis. Further progress is reported of the Shirley Developments, Ltd., the activities of which are now beginning to affect appreciably the rate of application of scientific advances by the industry. The British Electrical and Allied Industries Research Association has installed an automatic equipment for cyclic tests on joints with live steam at a power station, and in experiments on polythene cross-linked by high-energy radiation has discovered a new type of intrinsic breakdown in which the material fails mechanically under the electrostatic forces present. The British Hat and Allied Feltmakers' Research Association continued its study of damage to wool noils and a comprehensive large-scale study of the carrotting process. The Research Association of British Flour Millers continued to collaborate with the National Institute of Agricultural Botany in the effort to find wheat varieties of improved milling and baking quality, and also its work on the effect of improvers upon the quality of flour. The British 
Food Manufacturing Industries Research Association extended its study of the melting and crystallizing behaviour of cocoa butter and of possible alternative fats; and the Fruit and Vegetable Canning and Quick Freezing Research Association continued its work on the effect of conditions of cutting and drying of harvested peas on their texture when canned as processed peas.

Steady progress was made by the British Gelatine and Glue Research Association in fundamental investigations into the structure, properties and mode of formation of gelatin and animal glue; and the Hosiery and Allied Trades' Research Association's investigations on crimped nylon products promise to facilitate a more precise control of their 'handle' and elastic properties. The permanent fireproofing process developed in the British Jute Trade Research Association's Laboratories retains its effectiveness even after immersion in sea water for four to five weeks and also after four months free exposure to atmospheric conditions. Further work by the British Launderers' Research Association has confirmed the effect of traces of impurities in the fibres on the extent of dirt removal produced by detergent solutions. A method recently developed in the British Non-Ferrous Metals Research Association's laboratories allows the fatigue limit of many materials to be determined in a few hours with only one specimen, and the Association has also developed the use of the direct-reading spectrograph, the quantograph, in the analysis of copper and copper alloys. The Research Association of British Paint, Colour and Varnish Manufacturers is using autoradiography to examine the migration of plasticizer from synthetic latex paint films into wooden substrates, and continued a special programme on the adhesion of paint films to their substrates.

The work of the British Paper and Board Industry Research Association is making a material contribu. tion to scientific knowledge of the physical structure of papermaking fibres which it is hoped will lead to improved techniques for developing the physical characteristics in commercial pulp required to produce sheets of paper of satisfactory quality. A main object of the packaging research of the Printing, Packaging and Allied Trades Research Association is to improve the performance of packages so that they provide the maximum protection at the minimum cost. The British Rayon Research Association made further fundamental studies on the frictional properties of individual fibres with particular reference to the effect of diameter. The electromagnetic method of thickness-gauging devised by the British Scientific Instrument Research Association for use on lead-covered power cables has reached the stage of commercial exploitation.

The wide range of the contribution to industrial advance and to national welfare which the Depart. ment of Scientific and Industrial Research is making, both directly through its own research stations and indirectly through its support of the research associations and of fundamental research at the universities, is sufficiently illustrated by the foregoing examples. What should be no less apparent is that the real difficulty is to select from the many possible projects those on which public money can be spent to the best advantage. The increased provision made for the work of the Department over the past few years has not, in fact, permitted any real expansion: it. has scarcely balanced the mounting costs of research. While the present report does not supply all the information required for a sound judgment, it does indicate the need for some careful consideration of the exact functions of the Department and of its place in the national organization of research when the Bill now before Parliament to change its administrative and financial arrangements is debated.

\section{DETECTION AND DEVELOPMENT OF SCIENTIFIC ABILITY}

$\mathrm{O}$ N March 17, the British Social Biology Council held a conference on "Scientific Ability: its Detection and Development" at the London School of Economics. It was attended by a good number of teachers, representatives of Government departments, members of national organizations of a scientific nature, and representatives of industry. The purpose of the conference was to consider the influences acting on the minds of boys and girls in deciding whether or not to take up science; the ways in which scientific ability may be detected and developed; and the extent to which originality in science is subject to changing conditions. It brought to light three major points.

The first point was that although science is rapidly altering the material fabric of the economic world, and profoundly influencing all aspects of human culture, very little consideration is being given, at research level, to the nature of scientific ability itself and the conditions under which it develops. This is particularly true of Great Britain. Studies made in the past, chiefly in the United States, have little value in predicting scientific talent, since they fail to distinguish promise in this direction from that in other walks of human life, such as commerce, the arts and the professions. There is urgent need for new researches to be undertaken, drawing on the insights provided by recent progress in psychology.

The second point was that while latent intelligence is almost certainly inherited-a point that received no consideration at the conference-it is now fairly generally agreed that the manner in which it manifests itself is subject to influences of a personal and social nature. There does not appear to be any special mental characteristic that is essential for success in science; instead, given equal degrees of intelligence, the difference between the scientist and the artist, the teacher and the man of affairs, can be attributed to the accidents of family upbringing, educational training, and opportunities in the choice of a career. This realization carries with it a supplementary one that in varying degrees, depending on innate intelligence, there is still in the nation a large reservoir of potential scientific ability lying latentboth among boys, and to a still greater extent among girls, among whom its development presents special difficulties.

A third point was that owing to social pressures, tendencies that are recognized as being unfavourable continue in operation, on account of the absence 